\title{
The Impact of Learning Styles on Learner's Performance in E-Learning Environment
}

\author{
Manal Abdullah \\ Department of Computer Science \\ Faculty of Computing and Information Technology, FCIT \\ King Abdul-Aziz University, KAU \\ Jeddah, Saudi Arabia
}

Wafaa H. Daffa

Department of Computer Science

Faculty of Computing and Information Technology, FCIT

King Abdul-Aziz University, KAU

Jeddah, Saudi Arabia

\author{
Reem M. Bashmail \\ Department of Computer Science \\ Faculty of Computing and Information Technology, FCIT \\ King Abdul-Aziz University, KAU \\ Jeddah, Saudi Arabia
}

Mona Alzahrani

Department of Computer Science

Faculty of Computing and Information Technology, FCIT

King Abdul-Aziz University, KAU

Jeddah, Saudi Arabia

\author{
Malak Sadik \\ Department of Computer Science \\ Faculty of Computing and Information Technology, FCIT \\ King Abdul-Aziz University, KAU \\ Jeddah, Saudi Arabia
}

\begin{abstract}
E-Learning, personalization has emerged as important need. Differences of learners' abilities and their learning styles have affected the learning outcomes significantly. Meanwhile, with the development of E-Learning technologies, learners can be provided more effective learning environment to optimize their performance. The purpose of this study is to determine the impact of learning styles on learner's performance in e-learning environment, and use this learning style data to make recommendations for learners, instructors, and contents of online courses. Data analysis in this research represented by user performance gathered from an E-learning platform (Blackboard), where this user performance data is represented by actions performed by platform's users. A 10-fold cross validation was used to create and test the model, and the data was analyzed by the WEKA software. Classification accuracy, MAE, and the ROC area have been observed. The results show that the accuracy of classification by means of NBTree technique had the highest correct value at $69.697 \%$ and it could be applied to develop Felder Silverman's learning style while taking into consideration students' preference. Moreover, students' performance increased by more than $12 \%$.
\end{abstract}

Keywords-Learning style; Silverman; E-Learning; online learning; styling model

\section{INTRODUCTION}

The great population of the Internet and computer has affected the learning methodologies and education. Traditional education approaches have been changed using these new technologies. In fact the integration of new technologies in the field of education offers new challenges and opportunities in distance learning and e-learning in general. Online learning provides learners with more resources that cater to all needs in various fields of educations. Currently, various supporting technologies are available for teaching processes and learning practices in many universities and schools. This leads to an elearning paradigm.

The transformation of the teaching-learning practices to the e-Learning environment has attracted researchers to understand, examine and evaluate the role of the information and communication technologies in the learning environment. It is evident that learning and education differ greatly between learners due to their different preferences, needs and approaches to learning. Psychologists call these individual differences learning styles. Therefore, it is very important to accommodate for the different styles of learners through learning environments that they prefer and find more efficient.

Learning style could be a good predicator of an individual's preferred learning behavior and a good indicator of successful distance learning. Majority of the research conducted are based on the learning styles as these are the most dynamics and give the best results if catered to properly. In other words, understanding the learners' needs and identifying their patterns of learning are crucial to design e-learning material according to learners' learning styles and to bridge the gap resulting from unfamiliarity of a triangular community members i.e. learners, instructors, and contents of online settings. It is necessary to determine what is most likely to grasp each learner's attention, and how to respond to his/her natural understanding style to produce long-term remembering. The main challenge is the detection of the learning styles. Identifying learners' learning style has been considered as vital element. Teaching methodology should be, in turn, adjusted with online 
instruction and delivery [1]. Researchers have described various learning styles models such as Kolb [2], Honey \& Mumford [3], and Felder-Silverman [4].

Learning style affects how a student responds to stimuli and approaches new material. There are some ways that can use learning style data to enhance student's learning experience. Learning style data can be used to guide the student toward more effective study habits and that data can be used to help instructors in their selection of instructional strategies.

The system deals with information about learners and their learning activities to recommend the appropriate way to present the material for students based on their learning style and other data. This paper discusses the approach of intelligently detect student's learning style based on integrated Felder Silverman (IFS) learning style model, and then uses this data with Blackboard (BB) Learning Management system (LMS) to optimize student's learning outcomes.

The rest of this paper is organized as follows: In section2 Felder-Silverman learning style model (FSLSM) is introduced. Section 3 describes the combinations importance of electronic media and learning styles. Section 4 briefly presents some related work. Section 5, introduces proposed model. Section 6 , section 7 and section 8 respectively, present experimental procedure, results and discussion then concluding the paper and future work.

\section{FELDER-SilVERMAN LEARNING STYLE MODEL}

Over seventy identifiable approaches are used to investigate and describe learning style preferences. Felder-Silverman learning style model (FSLSM) has been the most popular model because it seems to be the most appropriate for use in computer-based educational systems [5]. FSLSM has the advantage of the sliding scales supporting a classification of student's style which is more flexible than bipolar models. Most other models classify learners in few groups, whereas FSLSM identifies the learning style and distinguishes between preferences on four dimensions. Each dimension includes two variables [6] as shown in figure 1. Data collection tool, called Index of Learning Styles (ILS) assesses variations in individual learning style preferences across four dimensions or domains.

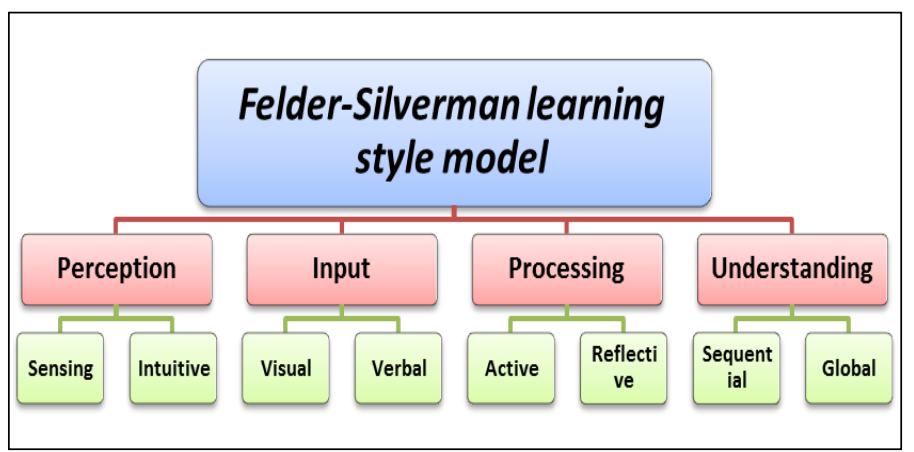

Fig. 1. Felder-Silverman Learning Style Model

\section{A. Index of Learning Styles (ILS) Felder Silverman}

The Index of Learning Styles (ILS), developed by Felder and Soloman, is 44 questions for identifying the learning styles according to FSLSM. As mentioned earlier, learner has a personal preference for each dimension. Each preference is expressed with a value between +11 to -11 . This range is computed based on the 11 questions that are posed for each dimension. When learner answers a question with an active preference, +1 is added to the value of the active/reflective dimension. Whereas if he answers with a reflective preference, this decreases the value by 1 . Therefore, each question changes total value for certain dimension with a value of +1 (answer a) or -1 (answer b). Answer a referes to the preference of the first pole for all dimensions (active, sensing, visual, or sequential), and answer $b$ referes to the second pole of all dimensions (reflective, intuitive, verbal, or global).

\section{B. Grouping of Silverman Model}

Each learning style of FSLSM is described by different characteristics. Based on this description [4], the questions in ILS are manually grouped according to the similarity of semantics. Each dimension distinguishes between two oppisite characteristics. Active/reflective dimension represents the way of processing information. The second dimension covers sensing/intuitive learning. The third, visual/verbal dimension differentiates learners who remember best what they have seen. The fourth dimension characterizes learners' understanding. Sequential learners understand in small incremental steps, therefore have a linear learning progress. According to this model, learning styles determine different sets of learning sequences for learners with different learning styles. So, $\mathbf{2}^{\mathbf{4}}=$ 16 different learning style are created by the combination of the four dimensions.

\section{Analyses of Semantic Groups}

To detect the most representative groups from the sixteen learning styles groups mensioed above, some analyses are performed based on data collected from the ILS questionnaire. Fisher discriminant analysis for linearly reducing dimensionality can be used to optimally separate the most representative semantic groups of each dimension. The research then compares the model given by Fisher discriminant analysis with some experimental results. Frequency and correlation analysis are performed in order to cross-validate the model used. It is also important to conduct some statistical analysis which transforms data to its absulute scale, that is frequecies. Let $\mathrm{Q}$ be the $25 \times 44$ matrix containing in rows instances of students and in columns the answer to each ILS question. For each question $\mathrm{q}_{\mathrm{i}}, \mathrm{Q}=44$, two numerical variables are allowed, $\mathrm{a}_{1}=1$ if $\mathrm{q}_{\mathrm{i}}=1$ (otherwise 0 ) and $\mathrm{a}_{2}=1$ if $\mathrm{q}_{\mathrm{i}}=-1$ (otherwise 0 ). Let $\mathrm{A}$ be the $40 \times 88$ matrix containing in rows individuals and in columns the $a_{i}, i=1, \ldots, 88$. The matrix $A$ has ranked at most 44 by construction, since two columns are constrained to sum up to 1 in rows. Fisher linear discriminant analysis (LDA) is then performed on the whole matrix A of learners' answers to ILS.

\section{LEARNING STYLE WITH ELECTRONIC MEDIA}

In the context of Information and Communication Technology ICT evolution and due to the wide spread of electronic media, making use of e-media with teaching and learning styles has facilitated the teaching process. Many researches studies the effectiveness of combining multimedia and hypermedia within educational systems [7] [8]. In these studies, authors associated specific e-media characteristics to 
different categories of learners and proposed tools and models for assessing learning style [9]. Most of these studies rely on Kolb's Learning Styles Inventory (LSI) [2] and SolomanFelder Index of Learning Styles (ILS) [10]. However, e-media as a learning object may be used with different implementations to adapt different learning styles. The combinations of different electronic media are examined by few researchers to decide the appropriate combinations for certain learning style which yield effective learner's performance. For example [6], discussion forum object combined with some problem solving object may be used to assign a practical task to students in such a way that students discuss the assigned problem in a collaborative manner. Sensitive learning style can benefit this combination. Sequential style students may also make use of discussion forum by communicating with the teacher through sequential series of presentations associated with the corresponding discussion.

\section{RELATED WORK}

Many educational software has been developed to match students' learning style with the appropriate learning objects. These can be broadly classified into two categories: (A) Adaptive systems that adapt the course object to learners' learning styles, and (B) Tutoring systems that suggest appropriate learning activities through different recommendation techniques. These recommendations are based on learner's preferences, knowledge and the browsing history of other learners with similar characteristics.

\section{A. Adaptation Systems to Learner's Learning Styles}

A lot of research work had been proposed for determining learning style of individuals dynamically. The dynamic changes of the behaviour and the knowledge level of an individual determine the his/her learning style. The studies can be broadly classified into two approaches: datadriven approach (using Bayesian Networks and NBTree classifiers) and literature-based approach. The literature-based approach investigates learners' behaviors in their interactions with LMSs. Some of the noticeable works have been summarized here. Garcia et al. [11] proposed a Bayesian network based model that is used to infer the learning styles of the students according to their modelled behavior, in order to adapt styles in Web-based education system. O polar and Akbar [12], proposed an automated learner model based on FSLSM learning styles classifier using NBTree classification in conjunction with Binary Relevance Classifier. Montazeri and Ghorbani [13] proposed an Evolutionary Fuzzy Clustering (EFC) methodology with Genetic Algorithm (GA) for the recognition of learning styles of e-learners. The work of Graf et al. [14] proposed a literature-based approach that automatically detects the learning styles in LMSs. Dung and Florea [15] tracked data of learners' behaviors and used simple mapping rule to infer learning styles against Felder-Silverman Learning Style Model.

\section{B. Systems with Implemented Recommendation}

Data mining techniques can be used to recommend elearning strategies by adapting learner's characteristics and preferences. Learner characteristics are such as learning styles, experince, knowledge etc. The "Adaptive Hypermedia Architecture", has been developed for providing online course recommendations [16]. Adaptation of presentation and navigation system based on specific prediction rules is used. Garcia et al. [11] extended their previous work by providing suggestions based on the learning styles of the students. An intelligent agent called eTeacher, was provided to help students at certain course through an eLearning system called SAVER. Example of recommendations advised to sequential learner are to read certain topic before reading another one. During the analysis, authors reported that $83 \%$ of the total feedback received was positive.

Beragasa-Suso et al. [17] designed a web browser-based system called iLessons. The system is embedded within Microsoft Internet Explorer enabling the teachers with various features such as reusing the materials available on the WWW by drag and drop, navigation options. The authors extended the iLessons system by assessing the students' learning styles based on FSLSM using the online available Index of Learning Styles (ILS) for recommending relevant web sites to the students. Finally, the active-reflective dimension, for examplr, was determined taking into account some parameters such as the ratio between the images and text of a page, the average time spent on a page, the scroll distance and direction changes and the mouse movements. These parameters were used to predict learner's learning style with an accurate rule.

Khiribi et al. [18] used learner navigational history and similarities among learners' preferences and educational contents to recommend the learning resources. The proposed framework is essentially based on two components: the Modeling phase and the Recommendation phase. Garth and Abdullah [19] introduced a novel architecture for an e-learning recommender system (ELRS) that is based on content-based filtering and good learners' ratings as learning materials recommendation method. Jyothi et al. in [20] stated that most of the existing studies used small datasets to build their models which cannot provide accurate results. They used the historical data to generate students' clusters. As a result, authors proposed a recommendation system to assist the instructor to identify clusters of learners who have similar learning styles identified by FSLSM rather than at the individual level. Milicevic et al. [21] proposed POTUS (Programming Tutoring System). This system used the interests and similar knowledge level of learners to recommend the learning contents for the student. Dwivedi and Bharadwaj [22] developed a weighted hybrid collaborative framework to recommend relevant learning contents to the learner by modeling learning style and the knowledge using collaborating filtering technique. 


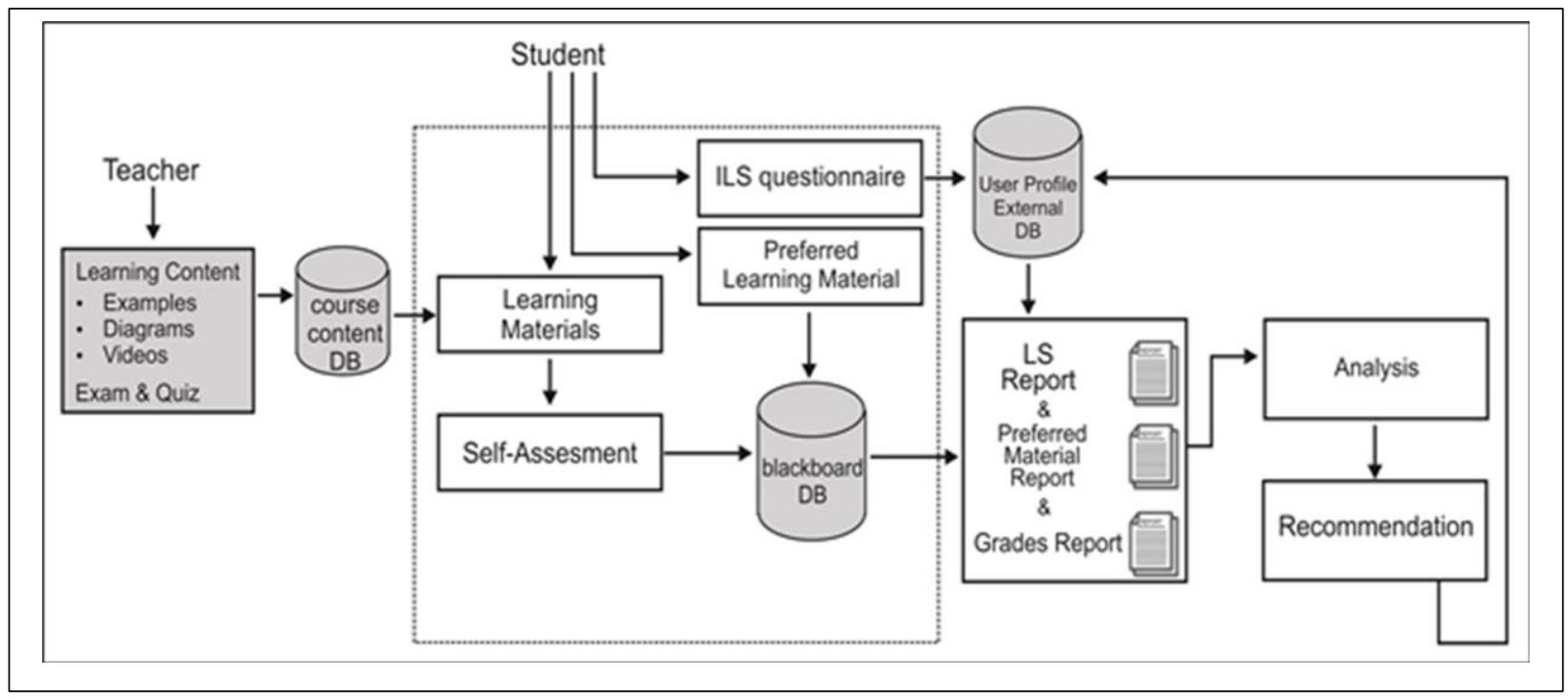

Fig. 2. Learning Style Blackboard Tracking System Model and Architecture

\section{PROPOSED MODEL}

The proposed model matches a student's particular learning style with the case method of teaching to influence course outcomes. This research aims to advise automatic recommendations to an active learner based on his/her learning style, grades and user preferred learning material.

Figure 2 shows the system architecture and design. The basic steps are; A) data collection and pre-processing, B) pattern discovery, and $C$ ) validation and interpretation. In the following, detailed explanation is presented.

\section{A. Data Collection and Pre-Processing}

The study was conducted on 33 learners, students of the Department of computer science at King Abdul-Aziz University. Three types of data is collected from learners: Learning style detection through questionnaire based on index of learning styles (ILS) developed by Felder and Soloman, quiz grade, and preferred learning style as the preferred learning method.

1) Learners need to complete the ILS questionnaire. This learning style questionnaire indicates a preference for some teaching case. Results are stored in the learner profile.

2) Learners have to log into the Blackboard system (BB), at the first-time, BB system is a leading Learning Management System LMS (or CMS) product used in North America and Europe. It is protected by a password environment and has administration tools that facilitate teaching online.

$\mathrm{BB}$ is Web-based server software. Some of its features include course management, customizable open architecture, and scalable design. Student information systems with authentication protocols are integrated to yield secured learning environment. Its main purposes are to develop online elements to courses traditionally delivered face-to-face, as well as providing users with a platform for communication and sharing contents.
3) After logging in, the BB system will display the "Course" screen as shown in figure 3. Students will be asked to complete a self-assessment test after completing the learning materials that have been assigned to them (Abstract, Overview, PowerPoint, Text, Videos \& Images, and Examples) to assess their learning gain. The learners' grading can be interpreted according to the percentage of correct answers, as follows: $(70-100 \%)$ is accepted, less than $70 \%$ is not accepted. The self-assessment grade is recorded in the Blackboard log and then stored in the learner profile.

4) The learner also needs to answer a short preferred learning style question that it used to determine his/her preferred learning material that most fulfill his requirements.

The profile table, shown as table 1, has eight columns in which first one is for user id. Next four columns are representing dimensions of the learning style model for ILS. Then next two columns are for self-assessment grade and learner's preferred learning materials. And last column is for recommended materials.

The data is then pre-processed and transformed into appropriate format (represented by numbers and stored in the form of CSV file.) in order to analyze and interpret the characteristics of the students based on Felder-Silverman learning dimensions.

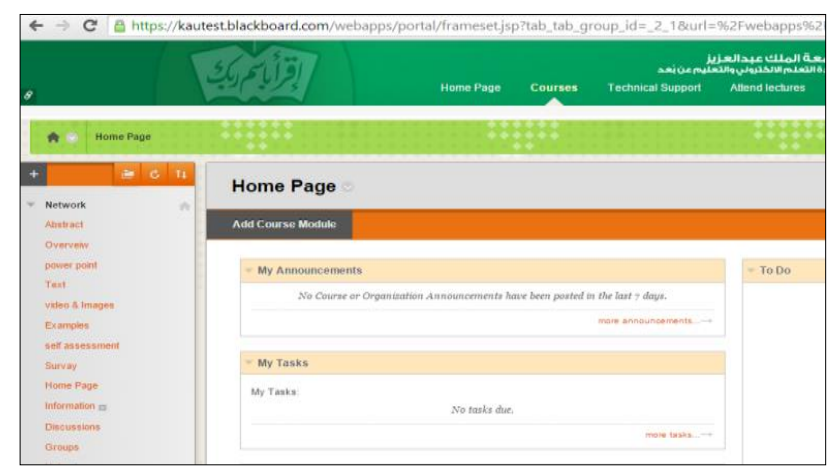

Fig. 3. Blackboard Learning Material Screenshot 


\section{B. Classification and Pattern Discovery}

The aim of the classifying is to assign labels to each row of the learner profile table using dimensions of the FSLSM. Since each learning style can be associated with an appropriate learning object based on Felder and Soloman characteristics [6] [12], as shown in table 2.

After classifying all learner profile tables, the total score for each scale is calculated using class label counts. Among them, the two related learning style scores for each FSLSM dimension label are compared for that dimension to predict the style. As an example, if the total score for the processing dimension (as Active) is higher than the score for the opposite pole (as Reflective), the participant is reported to be Active. The label with the highest score is assigned to the respective record, as shown by example in Table 1 .

Creation and test of the data classification model were conducted by WEKA data mining tool in order to infer the students' learning style. WEKA is developed by the University of Waikato in New Zealand [23] Using JAVA language. Various data mining algorithms are implemented by WEKA. These algorithms include data classification and regression. Also, clustering and association rules are exist. Bayes classifiers, Trees, Rules, Functions, Lazy classifiers and miscellaneous classifiers are examples of learning algorithms implemented in WEKA. WEKA normally uses ARFF file format.

TABLE I. SAMPLE LEARNER PROFILE

\begin{tabular}{|c|c|c|c|c|c|c|c|}
\hline \multirow{3}{*}{ id } & \multicolumn{4}{|c|}{ ILS } & \multirow{3}{*}{$\begin{array}{c}\text { Self- } \\
\text { assess } \\
\text { ment }\end{array}$} & \multirow{3}{*}{$\begin{array}{l}\text { Preferred } \\
\text { Learning } \\
\text { Material }\end{array}$} & \multirow{3}{*}{ material } \\
\hline & $\begin{array}{c}\text { Active/ } \\
\text { Reflecti } \\
\text { ve }\end{array}$ & $\begin{array}{c}\text { Sensing } \\
/ \\
\text { Intuitiv } \\
\mathrm{e}\end{array}$ & $\begin{array}{l}\text { Visual/ } \\
\text { Verbal }\end{array}$ & $\begin{array}{c}\text { Sequential/ } \\
\text { Global }\end{array}$ & & & \\
\hline & percept & Input & process & understand & & & \\
\hline 3 & $\% 27.27$ & $\%-9.09$ & $\% 100$ & $\% 45.45$ & $80 \%$ & Video & Video \\
\hline
\end{tabular}

The data in this research has been running on Bayes network classifier (Naïve Bayes) and classification tree with pruning algorithms (J48, NBTree).

WEKA data mining tool has $\mathrm{J} 48$ algorithm as an open source Java implementation of C4.5 algorithm, while C4.5 is decision tree based algorithm that is a software extension and improvement to the basic ID3 algorithm. The improvements done by C4.5 over ID3 include accounts for unavailable values, continuous attribute value ranges, pruning of decision trees, rule derivation, and others. A hybrid algorithm called NBTree is a combination of Decision Tree and Naïve-Bayes. NBTree uses the classical recursive partitioning schemes except for pruning where the leaf nodes create Naïve-Bayes groups instead of node predicting a single class. Based on the probability theory, NaïveBayes algorithm is a simple classifier that calculates a set of probabilities using frequencies and combinations of values in a given data set. The algorithm uses Bayes theorem assuming all attributes are independent given the value of the class variable. This conditional independence assumption rarely holds true in real world applications. Although this characterization as Naïve still valid, the algorithm tends to perform well with various supervised classification applications [24], [25].

\section{Model Validation}

In this research, the used classifiers are evaluated using a 10 -fold cross validation method. It divides a dataset into ten parts (folds), hold out each part in turn, and averages the results. Each data point is used once for testing, nine times for training. Finally, the results of the tests were compared in terms of students' performance.

\section{EXPERIMENTAL PROCEDURE}

Based on the flexibility offered in Blackboard, various learning resources have been developed for an active "Data Communication and Networking" CS course. To test the effect of using various types of resources depending on students learning styles. Network course is chosen because it is foundation course for CS major. It provides basic networking concepts, including network architecture, design, network protocols, and protocol suit.

The foundation of this study was conducted on 33 learners, students of the Department of computer science at King AbdulAziz University. Learners of the training dataset learned based on the extracted learning style; then it is required to complete self-assessment test to evaluate their understanding. However, relying on questionnaires for classifying students' learning styles has main disadvantage that not all the students are motivated to fill out the questionnaire. Hence, misleading answers of the questionnaire which are not the real behavior of the student could be reported [24]. To overcome these problems, a supportive method (one-question) is used to collect the most preferred learning material directly from students. Table 2 shown the relevance keywords for groups of learning styles

Direct learning style $\left(\mathrm{LS}_{\mathrm{D}}\right)$ and indirect learning style $\left(\mathrm{LS}_{\mathrm{IN}}\right)$ detection methods have been used to extract student's LS. The resulting classification tree is illustrated in Figure 4.If direct and indirect LS doesn't match, their percentage will be compared after giving $60 \%$ weight to indirect $\left(\mathrm{LS}_{\mathrm{IN}}\right)$ value as shown in Figure 5, where direct and indirect values indicate respectively, to the ILS questionnaire and the preferred learning style result.

\section{TABLE II. RELEVANCE KEYWORDS FOR CLASSES OF LEARNING STYLES}

\begin{tabular}{|c|c|}
\hline $\begin{array}{l}\text { Learning } \\
\text { styles }\end{array}$ & material \\
\hline active & Experimentally, pair work, usually, ordinary, interactive \\
\hline reflective & observation ,theory, theorem ,challenges, alone work \\
\hline sensing & $\begin{array}{l}\text { Practically, in real world applications ,experimental data } \\
\text { results }\end{array}$ \\
\hline intuitive & Theoretically ,in principal \\
\hline visual & Simulations, Videos, graphs, images, charts ,figures \\
\hline verbal & Forum, discussion board ,text \\
\hline Sequential & sequential ,outline ,first ,second, flowchart, detail \\
\hline global & Overall ,overview ,outlines, abstract, whole \\
\hline
\end{tabular}




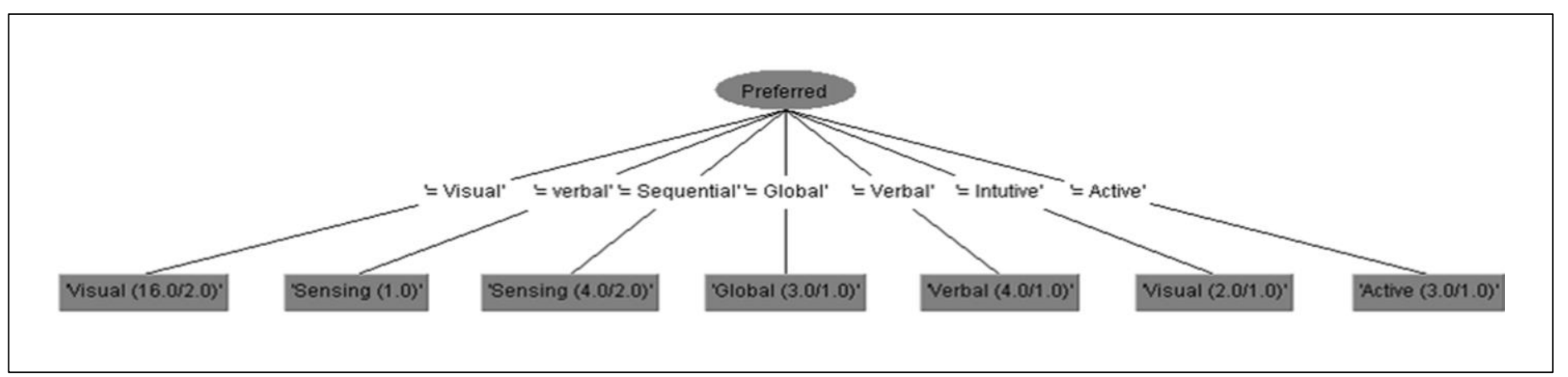

Fig. 4. Final Learning Style Classification Tree

During study session, learners from the training dataset were required to fill in the ILS questionnaire and the preferred learning style to explore self-study method in using e-learning system. They were also asked to take part in forum discussion and to acquire on-line quiz and on-line assessment. The material is introduced as power point presentations using powerful abstract and concrete learning materials. Animations, videos and simulations of some concepts can also be explored by the students. At the end of the tutorial, learners completed a self-assessment test, with the results being stored in the learner's profiles.

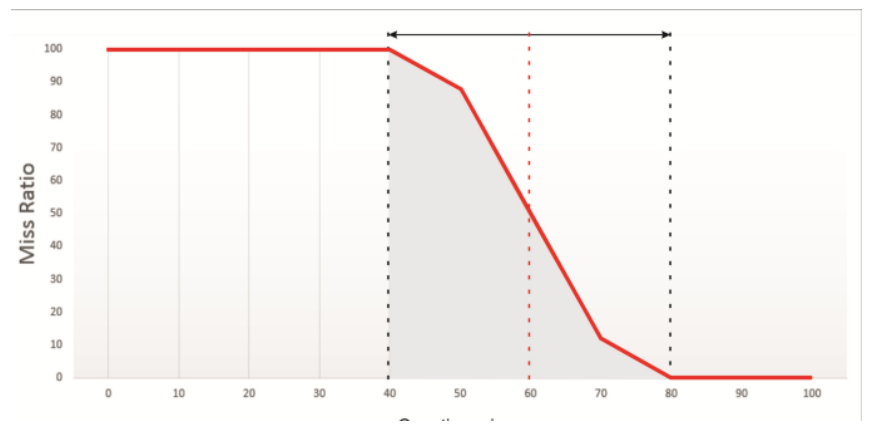

Fig. 5. Miss Ratio

\section{RESULTS AND DISCUSSION}

The ILS results, the number of correct answers as well as the learners' preferences in using the learning material have been analyzed. Table1 shows sample learner profile for these (FSLSM). Classifications were formed to determine learning styles for $90 \%$ learners from the training dataset. This way, the classifiers have been trained using $90 \%$ of the training data and evaluated their performance on the remaining 10\%. Algorithms namely classification tree have been selected with pruning algorithms J48, NBtree, and Naïve Bayes Classifier. Finally 10 -fold cross validation is used for every classifier. Since the amount of data available is limited, 10 -folds validation reduces the variance of the estimated performance. Averaging over 10 different partitions makes the estimated performance is less sensitive to the partitioning of the data.

The experimental results are shown in table 3 . It summarizes the results are recorded as correct and incorrect classified instances, Mean Absolut Error (MAE) and the weighted averages of True Positive rate (TP), False Positive rate (FP) and ROC area for each LS class. Mean Absolute
Error (MAE) has been used to measure the accuracy of the final LS. MAE can be defined as the deviation between the predicted LS and the proposed LS which is derived from ILS $\left(L S_{I N}\right)$ and preferred LS $\left(L S_{D}\right)$. The smaller MAE value indicates that the LS prediction is closer to the proposed LS and has a high accuracy. Accuracy is also measured by the area under ROC curve. A Receiver Operating Characteristic (ROC), is a graphical plot showing the performance of a binary classifier with varying discrimination threshold. The curve plots the true positive rate against the false positive rate at various threshold settings. An area of 1 represents a perfect test; an area of 0.5 represents a worthless test. A snapshot of NBTree output is shown in figure 6.

TABLE III. ClasSificATION ACCURACY AND TRAINING ERRORS

\begin{tabular}{|l|l|l|l|l|l|}
\hline Algorithm & $\begin{array}{l}\text { Correctly } \\
\text { Classified } \\
\text { Instances } \\
(\boldsymbol{\%})\end{array}$ & $\begin{array}{l}\text { Mean } \\
\text { absolute } \\
\text { error } \\
(\boldsymbol{\%})\end{array}$ & $\begin{array}{l}\text { Weighted } \\
\text { avg. TP }\end{array}$ & $\begin{array}{l}\text { Weighted } \\
\text { avg. FP }\end{array}$ & $\begin{array}{l}\text { Weight } \\
\text { ed av. } \\
\text { ROC }\end{array}$ \\
\hline J48 & 42.4242 & 0.2025 & 0.424 & 0.486 & 0.499 \\
\hline NBTree & 69.697 & 0.1599 & 0.697 & 0.302 & 0.844 \\
\hline $\begin{array}{l}\text { Naïve } \\
\text { Bayes }\end{array}$ & 69.697 & 0.1625 & 0.697 & 0.302 & 0.83 \\
\hline
\end{tabular}

The final learning style classification can be seen by means of NBTree and NaiveBayes. It had an accuracy of $69.697 \%$, with the value of MAE 0.1599 and 0.1625 , respectively. Both classifiers had higher accuracy than J48. This percentage is expected to increase as the sample size increases. It is also discovered that the lowest error is found in NBTree, while the rest of the algorithms ranging around 0.1625 and 0.2025 error. The algorithm with lower error rate has more powerful classification capability, hence it is the preferred algorithm for use. Among these classifiers, NBTree has the highest weighted average ROC, 0.844. Figure 6 shows a snap shot of the NBTree classifier output and its area under ROC is shown in Figure 7.

Finally, evaluating the system, differences in selfassessment grades and material preference between learners' studies have been investigated with different learning style materials. Therefore, two plots illustrated for 12 students (match). The first represents the matching between Direct and Indirect learning styles for the self-assessment grades among the corresponding number of students (count) as shown in Figure 8. The second represents the matching between Direct and Final learning styles for each self- assessment grades along with the corresponding number of student (count) as shown in Figure 9. 


\begin{tabular}{|c|c|c|c|c|c|c|c|}
\hline \multicolumn{8}{|c|}{$===$ Stratifled cross-validation $==$} \\
\hline \multicolumn{3}{|c|}{ Correctly Classified Instances } & \multicolumn{2}{|l|}{23} & 69.697 & $\frac{8}{8}$ & \\
\hline \multicolumn{3}{|c|}{ Incorrectly Classified Instances } & \multicolumn{2}{|l|}{10} & 30.303 & 8 & \\
\hline \multicolumn{3}{|c|}{ Kappa statistic } & \multicolumn{2}{|c|}{0.432} & & & \\
\hline \multicolumn{3}{|c|}{ Mean absolute error } & \multicolumn{2}{|c|}{0.432} & & & \\
\hline \multicolumn{3}{|c|}{ Root mean squared error } & \multicolumn{2}{|c|}{0.285} & & & \\
\hline \multicolumn{3}{|c|}{ Relative absolute error } & \multicolumn{2}{|c|}{71.6559 \& } & & & \\
\hline \multicolumn{3}{|c|}{ Root relative squared error } & \multicolumn{2}{|c|}{86.5405 \& } & & & \\
\hline \multicolumn{3}{|c|}{ Total Number of Instances } & 33 & & & & \\
\hline \multicolumn{3}{|c|}{ Ignored Class Unknown Instances } & \multicolumn{2}{|r|}{1} & & & \\
\hline \multicolumn{8}{|c|}{$===$ Detailed Accuracy By Class === } \\
\hline & TP Rate & FP Rate & Precision & Recall & F-Measure & ROC Area & Class \\
\hline & 0.947 & 0.5 & 0.72 & 0.947 & 0.818 & 0.87 & Visual \\
\hline & 0.6 & 0.071 & 0.6 & 0.6 & 0.6 & 0.8 & Sensing \\
\hline & 0 & 0 & 0 & 0 & 0 & 0.844 & Global \\
\hline & 0.333 & 0.033 & 0.5 & 0.333 & 0.4 & 0.892 & Verbal \\
\hline & 0 & 0 & 0 & 0 & 0 & 0.578 & Sequentj \\
\hline & 0.5 & 0 & 1 & 0.5 & 0.667 & 0.891 & Active \\
\hline Weighted Avg. & 0.697 & 0.302 & 0.612 & 0.697 & 0.639 & 0.844 & \\
\hline \multicolumn{8}{|c|}{$===$ Confusion Matrix $===$} \\
\hline$a b c c d$ & e f $<-$ & - classifie & d as & & & & \\
\hline $\begin{array}{llll}18 & 0 & 0 & 1\end{array}$ & $001 \quad a$ & = Visual & & & & & \\
\hline 2300 & $001 \mathrm{~b}$ & = Sensing & & & & & \\
\hline
\end{tabular}

Fig. 6. NBtree Classifier Output

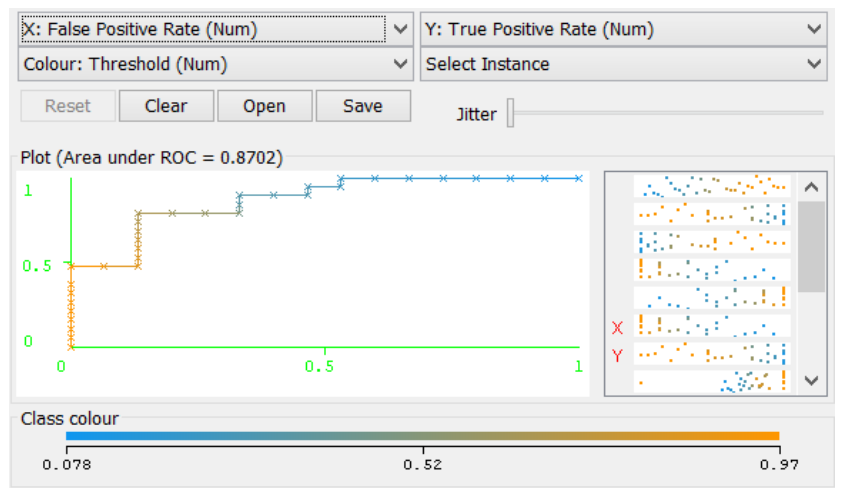

Fig. 7. Area under ROC

When the proposed LS is recommended to student then the direct LS would be more likely to match the final LS. Students' performance will be also improved as predicted by the classifiers (Figure 10). These have showed that incorporating learners' preference improves learner's performance.

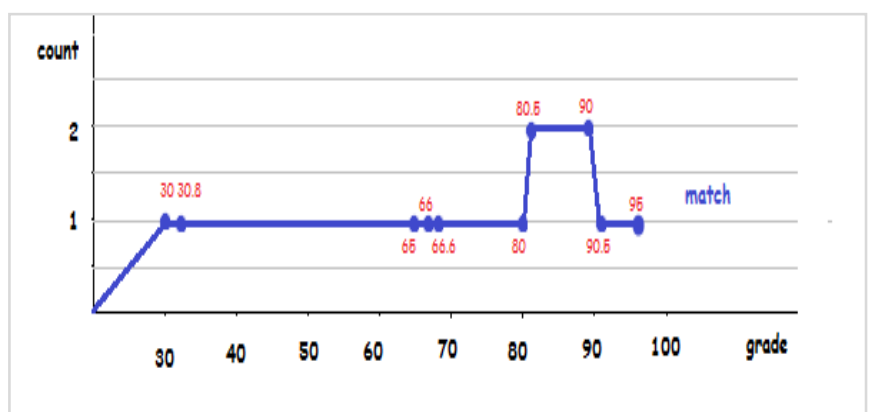

Fig. 8. Curve of Match Learning Styles between Direct and Indirect Styles

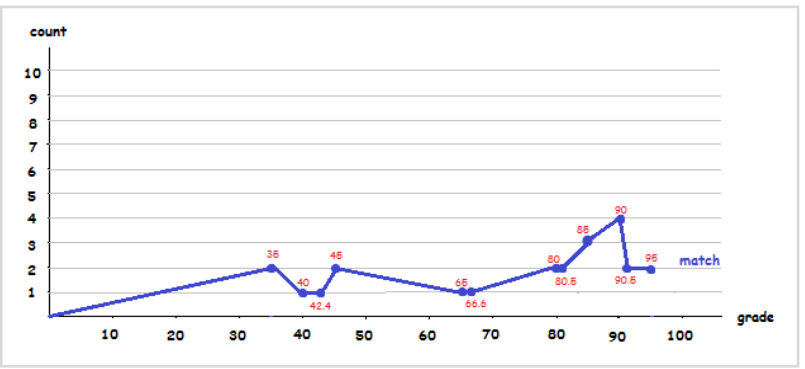

Fig. 9. Curve of Match Learning Styles between Direct and Final Styles

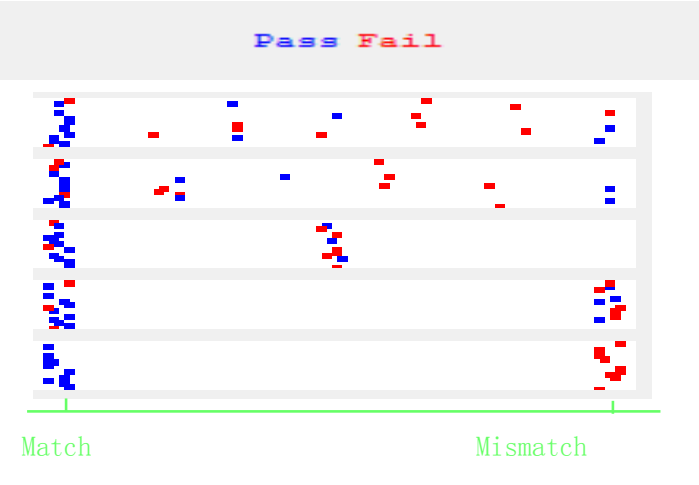

Fig. 10. Students Performance

\section{CONCLUSION AND FUTURE WORK}

This paper introduced the effect of Learning Styles LS on learners in E-Learning environment based on proposed model created from FSLSM and the preferred learning style question to detect more accurate result than using only Felder-Silverman learning style model.

Experimental results showed that when taking into consideration the student's choice and including students' preferred learning style to the learning style detection method, students' performance could be increased by more than $12 \%$ as shown in Figure 10. The proposed approach had an accuracy of $69.697 \%$, with the value of MAE 0.1599 and a weighted average ROC, 0.844 . These results are expected to improve when increased the sample size.

Future work will extend this work by developing and providing adaptive modules for the online learning system. Modifying courses automatically, adding some learning objects, and/or some learning activities are some features which can be added in order to make system fits to students' learning styles. Furthermore, researchers would plan using advanced methods of student's pattern collection, such as students' navigation behavior in a learning system, patterns related to some other types of learning objects/activities, and so on. Also, apply the research model and architecture to other LMS is planned.

REFERENCES

[1] C. Shih, J. Gamon, "Relationships Among Learning Strategies, Patterns, Styles and Achievement in Web-Based Courses," Journal of Agricultural Education, vol. 43, pp. 1-11, 2002.

[2] D. Kolb, Experiential learning: Experience as the source of learning and development: Prentice Hall, 1984. 
[3] P. Honey, A. Mumford, The Manual of Learning Styles Maidenhead, 1986.

[4] R. M. Felder , L. Silverman, "Learning and Teaching Styles in Engineering Education," Engr. Education, 78(7), 674-681, 1988.

[5] C. Carver, R. Howard, W. Lane, "Addressing Different Learning Styles through Course Hypermedia," vol. 42, pp. 33-38, 1999.

[6] A. Franzoni, S. Assar, "Student Learning Styles Adaptation Method Based on Teaching Strategies and Electronic Media," Educational Technology \& Society, vol. 12, 2009.

[7] L. NAJJAR, "Multimedia Information and Learning," Jl. of Educational Multimedia and Hypermedia, vol. 5, 1996.

[8] Y. Liao, "Effects of Hypermedia on Students' Achievement:A MetaAnalysis," JI. of Educational Multimedia and Hypermedia, vol. 8, 1999.

[9] R. Riding , S. Rayner, Cognitive styles and learning strategies: Understanding style differences in learning and behaviour: David Fulton Publishers, 1998.

[10] B. Soloman, R. Felder. (1993). Index of Learning Styles (ILS). Available: http://www4.ncsu.edu/unity/lockers/users/f/felder/public/ILSpage.html

[11] S. García, "An enhanced Bayesian model to detect students' learning styles inWeb-based courses," Journal of Computer Assisted Learning, vol. 14, pp. 305-315, 2008.

[12] G. Özpolat, "Automatic detection of learning styles for an e-learning system," Computers \& Education, vol. 53, pp. 355-367, 2009.

[13] G. Ghorbani, "Learners Grouping in E-Learning Environment Using Evolutionary Fuzzy Clustering," International Journal of Information and Communication Technology, vol. 3, pp. 9-19, 2011.

[14] S. Graf, Kinshuk; L. Tzu-Chien "Identifying Learning Styles in Learning Management Systems by Using Indications from Students' Behaviour," 2008.
[15] A. Dung, "An approach for detecting learning styles in learning management," presented at the International Conference on Education and Management Innovation, Singapore, 2012.

[16] De Bra, T. Santic, P. Brusilovsky ,"AHA! The adaptive hypermedia architecture," ACM, 2003.

[17] D. Sanders, J. Bergasa-Suso, "Inferring Learning Style from the Way Students Interact With a Computer User Interface," IEEE Transaction on Education, vol. 53, pp. 613-620, 2010.

[18] M. Khribi, M. Jemni, O. Nasraoui, "Automatic Recommendations for ELearning Personalization Based on Web," 2009.

[19] K. Ghauth, N. Abdullah, "The Effect of Incorporating Good Learners' Ratings in e-Learning Contentbased Recommender System," Educational Technology \& Society, vol. 14, pp. 248-257, 2011.

[20] N. Jyothi, K. Bhan, U. Mothukuri,S. Jain, "A Recommender system assisting instructor in building learning path for," 2012.

[21] B. Vesin, M. Ivanović, Z. Budimac A. Klasnja-Milicevic, "E-Learning personalization based on hybrid recommendation strategy and learning style identification," Computers \& Education, Elsevier Ltd, vol. 56, pp. 885-899, 2010.

[22] P. Dwivedi, , K. Bharadwaj, "Effective Trust-aware E-learning Recommender System based on Learning," Educational Technology \& Society, vol. 16, pp. 201-216, 2013.

[23] "Weka 3: Data Mining Software in Java ", http://www.cs.waikato.ac.nz/ml/weka/

[24] T. Patil and S. Sherekar, "Performance analysis of naïve Bayes and J48 classification algorithm for data classification," International Journal of Computer Science and Applications, vol. 6, pp. 256-261, 2013.

[25] P. Pumpuang, A. Srivihok, P. Praneetpolgrang, "Comparisons of classifier algorithmss: Bayesian network, C4.5, decision forest and NBTree for course registration planning model of undergraduate students," IEEE International Conference on Systems, Man and Cubermetics (SMC), 2008. 